\title{
Passive Structural Acoustic Control of the Smart Plate - FEM Simulation
}

\author{
M.S. KOZIEŃ ${ }^{a, *}$ AND J. WICIAK ${ }^{b}$ \\ ${ }^{a}$ Cracow University of Technology, al. Jana Pawła II 37, 31-864 Kraków, Poland \\ ${ }^{b}$ AGH University of Science and Technology, al. Mickiewicza 30, 30-059 Kraków
}

\begin{abstract}
Finite element simulations of passive damped system applied to the simply-supported excited squared steel plate, is the aim of the analysis. The full mechanical, piezoelectric, electric and acoustic field coupling is analysed in Ansys Package. As the result the acoustic pressure radiated by plate is analysed. The results show possibility of application of the discussed method to reduction of the sound pressure level in realistic engineering structures.
\end{abstract}

PACS numbers: 33.15.Mt, 34.50.Ez, 77.22.Gm

\section{Introduction}

The commonly used surface structural elements in mechanical systems are plates. The vibrating plates are source of noise radiation [1]. In the last times the interesting method of reduction of its vibrations is using piezoelectric elements bonded to plate. They are together built the so-called smart structures. Control of the piezoelectric elements can be done in two methods: the active one and the passive one. The basis of passive attempt is similar to the mechanical Frahm dynamic dampers. The damping electric $R L C$ circuit is dedicated to the chosen frequency. Usually it is the most important frequency of structural vibration e.g. the basic natural frequency. The general ideas of noise and vibration damping are discussed by Elliott and Nelson [2]. Granier et al. [3] and Moheimani and Fleming [4] present ideas of passive piezoelectric damping systems. Filipek and Wiciak [5] discuss possibilities of application of passive method for damping vibrations in beams. The field electron microscopy (FEM) Ansys simulations of passive damping system applied to the simply supported excited squared steel plate with one pair of piezoelectric elements, is the aim of the analysis. The full mechanical, piezoelectric, electric and acoustic field coupling is analysed in Ansys package. As the result a space distribution of the acoustic pressure around plate is analysed. The results show possibility of application of the discussed method to reduction of the sound pressure level in realistic engineering structures. Application of the $R L C$ system can be generalised for set of frequencies as the multimodal concept $[4,6]$.

\section{General idea of passive damping by piezoelectric elements}

The idea of passive damping of plates by piezoelectric elements is the analogy to the mechanical Frahm dynamic

\footnotetext{
* corresponding author; e-mail: kozien@mech.pk.edu.pl
}

dampers. Instead of spring and viscoelastic damper the resistance and inductance is applied. Having in mind that the piezoelectric elements have their own capacitance, the $R L C$ electric circuit is made (Fig. 1). The vibration energy, which, due to deformation, produces the electrical charge in piezoelectric elements is transformed into heat in the resistor $R$.

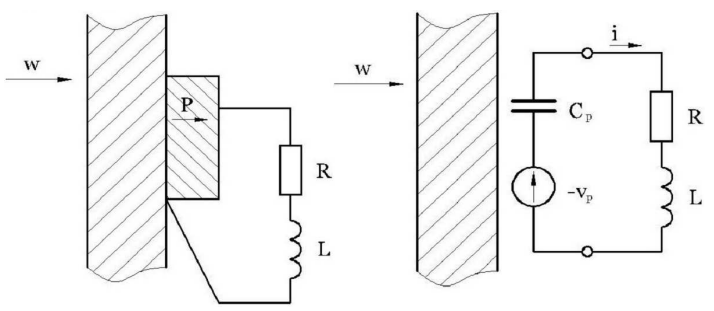

Fig. 1. Electric $R L C$ circuit for passive damping of structural vibrations.

The electric circuit should be designed for the only one frequency, usually natural frequency of structural system. For damping of a few natural frequencies, set of $R L C$ circuits must be designed $[4,7]$. The optimal values of the coil inductance $L$ are obtained assuming the FEM calculated capacitance of the piezoelectric elements $C_{\mathrm{p}}$. The optimal resistances $R$ are estimated based on the Hagood and von Flotow procedure having in mind the coefficient of electro-mechanical coupling $K_{31}$ [8].

\section{The hybrid method}

Theoretical background of the method is given in the papers $[7,8]$. The method gives possibility to estimate the acoustic intensity vector $\boldsymbol{I}$ in chosen point in acoustic space by the only knowledge of the amplitudes of vibrations of a set of areas for a given frequency $\omega$. The analysis is performed in the complex space.

The vibrating area is previously divided into the sub-areas. Each of the vibrating elements are the source of 
radiated sound for given frequency. The assumption of the method is that every sub-area is the small surface element. The "smallness" of the element is interpreted here in relation to the wavelength (associated with the wave frequency), in accordance with (1), where $r_{0}$ is the radius of the sub-domain or the greatest distance between the sub-domain centre and its boundary points $[1,9]$.

$$
r_{0} \ll \frac{\lambda}{4 \pi} \text {. }
$$

The analysis is described in Cartesian coordinate system Oxyz. Position of the chosen control point $P(x, y, z)$ is given by the vector $\boldsymbol{R}=\boldsymbol{O P}$, and position of the center of the $i$-th sub-area $Q_{i}\left(x_{i}, y_{i}, z_{i}\right)$ by the vector $\rho_{i}=\boldsymbol{Q} \boldsymbol{Q}_{i}$ (Fig. 2).

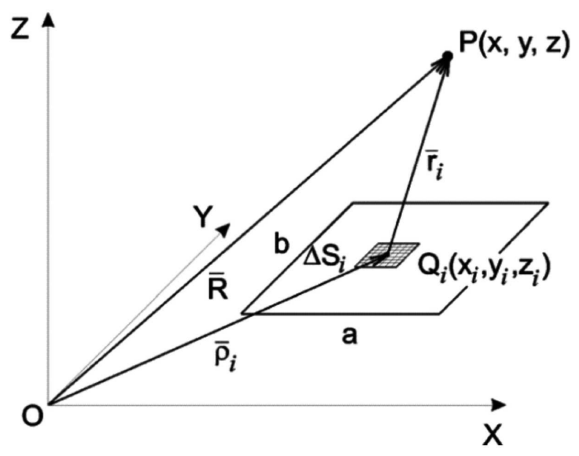

Fig. 2. Geometry of the sub-area and the control point.

For such a case the acoustic pressure and the partial velocity vector generated by $i$-th sub-area in the control point $P(x, y, z)$ can be obtained based on the following formulae $[1,10,11]$, where $\Delta S_{i}$ is the area of the $i$-th sub-area, and $A_{i}$ is the amplitude of its vibrations:

$$
\begin{aligned}
& \boldsymbol{v}_{i}=A_{i} \Delta S_{i}\left(-\frac{\omega^{2}}{2 \pi c r_{i}}+\mathrm{i} \frac{\omega}{2 \pi r_{i}^{2}}\right) \exp \left(\mathrm{i}\left(\omega t-k r_{i}\right)\right) \frac{\boldsymbol{r}_{i}}{r_{i}}, \\
& p_{i}=-\frac{1}{2 \pi} \Delta S_{i} \omega^{2} \rho \frac{A_{i}}{r_{i}} \exp \left(\mathrm{i}\left(\omega t-k r_{i}\right)\right) .
\end{aligned}
$$

The superposition of the components of pressures and partial velocities coming from set of sub-areas in resultant form in the analysed point $P$ are done by relationship, formulated previously by Mann et.al [12] for the set of $N$ point acoustic sources

$$
\bar{I}=\frac{1}{2} \sum_{j=1}^{N} p_{j} \sum_{j=1}^{N} \bar{v}_{j}^{*} .
$$

Based on the relationships (2) and (3), there are obtained formulae for the components of the real and imaginary parts of the resultant complex acoustic intensity vector in the chosen control point $[9,10]$. If the values of the acoustic pressure in a chosen point is the most important it can be obtained in approximate way based on the assumption of the plane acoustic wave in the control point area, in the form

$$
\begin{aligned}
& I=\frac{p^{2}}{\rho_{0} c}, \\
& L_{p}=10 \log \sqrt{\left[10^{\frac{L_{I x}}{10}}\right]^{2}+\left[10^{\frac{L_{I y}}{10}}\right]^{2}+\left[10^{\frac{L_{I z}}{10}}\right]^{2}} .
\end{aligned}
$$

\section{FEM model}

The FEM simulations are done for the simply supported aluminum square plate with one pair of centrally distributed piezoelements. It is in comparison with the previous analysis done for the four pairs of piezoelectric elements for the same structure $[11,12]$. The dimension of plate is: $0.1 \times 0.1 \times 0.002 \mathrm{~m}^{3}$. The piezoelectric materials with dimension $0.02 \times 0.02 \times 0.001 \mathrm{~m}^{3}$ are made of PZT4. The modal damping was 0.005 .

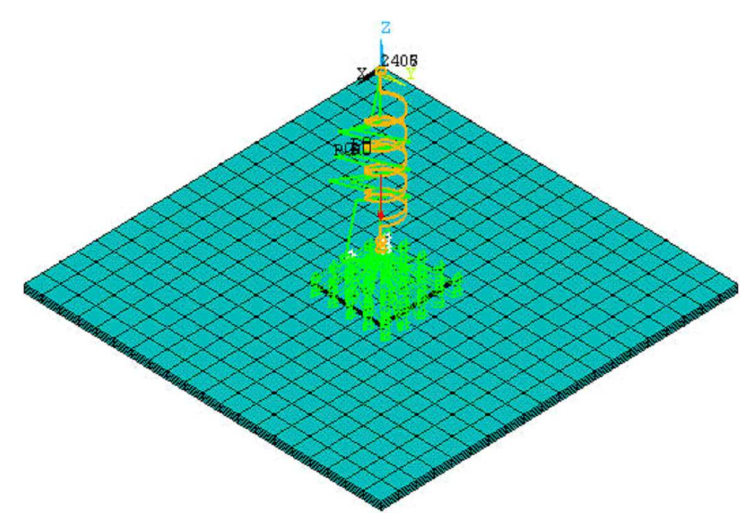

Fig. 3. Finite element mesh with $R L C$ elements.

The analysis is performed in the Ansys Finite Element package. The elements type: solid 5, solid 45 and circus 94 are applied. The mesh is shown in Fig. 3.

\section{Results of analysis}

The analysis was done for the first four natural frequencies. Modal analyses done for the open and short circuits gave possibilities to determine the optimal values of resistance and inductance. Then the analysis of excited vibrations for the separately analysed natural frequencies were done. External excitation was simulated by putting harmonically variable force into point with coordinates $[0.025,0.025]$ with amplitude $10 \mathrm{~N}$. At least the realistic and imaginary parts of the acoustic intensity vector in the control points distributed on the line perpendicular to plate in its central point are estimated by the hybrid method.

The results of analyses for the lowest three modes are given in Tables I-III, as results in a few points distanced $0.25,0.5,1.0$ and $2.0 \mathrm{~m}$ over plate. By reduction of the acoustic intensity it is understood the reduction of its realistic part. 
Real and imaginary parts of the intensity acoustic vector

TABLE I for the first natural frequency $f=1632 \mathrm{~Hz}$.

\begin{tabular}{c|c|c|c|c|c}
\hline \hline \multirow{2}{*}{$\begin{array}{c}\text { Distance } \\
\text { from plate } \\
{[\mathrm{m}]}\end{array}$} & \multicolumn{2}{|c|}{$\begin{array}{c}\text { No passive } \\
\text { damping }\end{array}$} & \multicolumn{2}{|c|}{$\begin{array}{c}\text { Passive } R L \\
\text { damping }\end{array}$} & \multirow{2}{*}{$\begin{array}{c}\text { Reduction } \\
{[\mathrm{dB}]}\end{array}$} \\
\cline { 2 - 5 } & $\operatorname{Re}(I)[\mathrm{dB}]$ & $\operatorname{Im}(I)[\mathrm{dB}]$ & $\operatorname{Re}(I)[\mathrm{dB}]$ & $\operatorname{Im}(I)[\mathrm{dB}]$ & \\
\hline 0.25 & 105.4 & 96.6 & 102.7 & 93.9 & \\
0.5 & 99.4 & 87.6 & 96.8 & 85.0 & \multirow{2}{*}{2.7} \\
1.0 & 93.4 & 78.6 & 90.8 & 76.0 & \\
2.0 & 87.4 & 69.6 & 84.8 & 67.0 & \\
\end{tabular}

Real and imaginary parts of the intensity acoustic vector

TABLE II for the second natural frequency $f=3667 \mathrm{~Hz}$.

\begin{tabular}{c|c|c|c|c|c}
\hline \hline \multirow{2}{*}{$\begin{array}{c}\text { Distance } \\
\text { from plate } \\
{[\mathrm{m}]}\end{array}$} & \multicolumn{2}{|c|}{$\begin{array}{c}\text { No passive } \\
\text { damping }\end{array}$} & \multicolumn{2}{|c|}{$\begin{array}{c}\text { Passive } R L \\
\text { damping }\end{array}$} & \multirow{2}{*}{$\begin{array}{c}\text { Reduction } \\
{[\mathrm{dB}]}\end{array}$} \\
\cline { 2 - 5 } & $\operatorname{Re}(I)[\mathrm{dB}]$ & $\operatorname{Im}(I)[\mathrm{dB}]$ & $\operatorname{Re}(I)[\mathrm{dB}]$ & $\operatorname{Im}(I)[\mathrm{dB}]$ & \\
\hline 0.25 & 135.4 & 123.1 & 129.6 & 117.3 & \\
0.5 & 129.5 & 114.2 & 123.7 & 108.4 & \multirow{2}{*}{5.8} \\
1.0 & 123.5 & 105.2 & 117.7 & 99.4 & \\
2.0 & 117.5 & 96.2 & 111.7 & 90.4 &
\end{tabular}

Real and imaginary parts of the intensity acoustic vector

TABLE III for the third natural frequency $f=6080 \mathrm{~Hz}$.

\begin{tabular}{c|c|c|c|c|c}
\hline \hline \multirow{2}{*}{$\begin{array}{c}\text { Distance } \\
\text { from plate }\end{array}$} & \multicolumn{2}{|c|}{$\begin{array}{c}\text { No passive } \\
\text { damping }\end{array}$} & \multicolumn{2}{|c|}{$\begin{array}{c}\text { Passive } R L \\
\text { damping }\end{array}$} & \multirow{2}{*}{$\begin{array}{c}\text { Reduction } \\
{[\mathrm{dB}]}\end{array}$} \\
\cline { 2 - 5 } & $\operatorname{Re}(I)[\mathrm{dB}]$ & $\operatorname{Im}(I)[\mathrm{dB}]$ & $\operatorname{Re}(I)[\mathrm{dB}]$ & $\operatorname{Im}(I)[\mathrm{dB}]$ & \\
\hline 0.25 & 137.0 & 122.3 & 132.3 & 117.7 & \\
0.5 & 131.1 & 113.6 & 126.4 & 108.9 & 4 \\
1.0 & 125.1 & 104.6 & 120.4 & 99.9 & \\
2.0 & 119.1 & 95.6 & 114.4 & 90.9 & \\
& & & & &
\end{tabular}

\section{Conclusions}

Results of the discussed analyses and the previously done by the authors make possibilities to formulate the following concluding remarks:

- It is possible to apply the passive method to reduction of plate vibrations having in mind minimization of radiated noise. The obtained reduction is in the range $3-6 \mathrm{~dB}$.

- Application of the only one pair of piezoelectric elements makes possible reduction of radiated noise. The position of piezoelectric elements is important.

- Noise reduction is lower than possible to obtain in active method with piezoelectric elements.

\section{References}

[1] M.S. Kozień, J. Wiciak, Acta Phys. Pol. A 116, 348 (2009).

[2] S.P. Elliott, P.A. Nelson, Active Control of Vibrations, Academic Press, London 1997.
[3] J.J. Granier, R.J. Hundhausen, G.E. Gaytan, Proc. SPIE 1, 237 (2001).

[4] S.O.R Moheimani, A.J. Fleming, Piezoelectric Transducers for Vibration Control and Damping, Springer, London 2006.

[5] R. Filipek, J. Wiciak, Arch. Mech. Eng. LIII, 21 (2006).

[6] M.S. Kozień, J. Theor. Appl. Mech. 47, 411 (2009).

[7] M.S. Kozień, J. Theor. Appl. Mech. 43, 119 (2005).

[8] N.W. Hagood, A. von Flotow, J. Sound Vibrat. 146, 243 (1999).

[9] M. Kwiek, Laboratory Acoustics, Vol. 1, Basis of Theoretical Acoustics, PWN, Warszawa 1968 (in Polish).

[10] Z. Piotrowski, Acta Phys. Pol. A 116, 375 (2009).

[11] A. Snakowska, Acta Phys. Pol. A 116, 410 (2009).

[12] J.A.III Mann, J. Tichy, A.J. Romano, J. Acoust. Soc. Am. 82, 17 (1987). 